\title{
RENATURALIZAÇÃO DE CÓRREGOS E RIOS URBANOS
}

\author{
Bruno Carneiro \\ Guilherme Frajdrajck \\ Isabela Abrão \\ Letícia Silva \\ Luiza Dutra \\ Liliane Frosini Armelin \\ Universidade Presbiteriana Mackenzie (UPM)
}

\begin{abstract}
Resumo
A renaturalização é a recuperação de um rio ou córrego com o restabelecimento de algumas de suas características naturais. A implantação dessa técnica nas cidades busca, além de integrar o recurso hídrico à paisagem urbana, resgatar um recurso que desapareceu com o avanço da urbanização e consequente necessidade de espaço. A poluição dos rios por esgoto doméstico contribuiu muito para o fechamento dos recursos hídricos que eram vistos como locais degradados, sob o ponto de vista ambiental, e causadores de doenças. Com a melhora nos sistemas de esgotos das cidades, houve uma mudança neste cenário e a implantação da renaturalização, que também pode minimizar problemas de inundação resultantes da excessiva impermeabilização do solo das áreas urbanas. Como forma de manutenção do entorno do corpo hídrico, pode-se considerar a implantação de obras que aproximem o rio da população, como o parque linear, permitindo a interação com o local e desenvolvimento de uma conscientização de preservação ambiental. Esta pesquisa demonstra, por meio da elaboração de um projeto de renaturalização de um rio existente na regiáo metropolitana de São Paulo, que a técnica pode ser possível mesmo em uma grande cidade, desde que sejam realizados estudos preliminares da região, tornando o projeto de implantação viável e garantindo benefícios.
\end{abstract}

Palavras-chave: Renaturalização. Parque linear. Drenagem urbana. 


\section{INTRODUÇÃO}

A renaturalização e revitalização de rios e córregos urbanos vêm ganhando espaço nos debates atuais, não só pelo estado de alerta em que está a maioria das grandes cidades atualmente, mas por todos os benefícios que poderiam ser adquiridos por esses métodos e a maior conscientização da população. Alguns pontos sobre o tema podem ser observados e discutidos, como os motivos que levaram a essa necessidade, às técnicas de implantação e aos exemplos de sucesso.

A drenagem urbana consiste, basicamente, em captar águas pluviais e levá-las corretamente ao seu destino final, processo que está relacionado a alguns dos principais problemas das grandes cidades. Sua insuficiência e, em alguns casos, ausência pode causar alagamentos, deslizamentos, transmissão de doenças, entre outros. Alguns desses problemas são normalmente solucionados com canalizaçóes de rios, porém, a longo prazo, essa pode não ser a melhor alternativa por causar outros problemas, por exemplo, ambientais.

A renaturalização de um rio consiste na sua recuperação como um todo e na recuperação de algumas de suas características que existiam antes de obras necessárias para atender às necessidades das cidades, como a retificação e canalização. Para Esposi, Takada e Silva (2016), a renaturalização de um corpo hídrico não significa a retomada da sua paisagem original. Segundo Tucci (2003 apud BRONCANELI; STUEMER, 2008), na década de 1970 , países desenvolvidos notaram que os custos com a canalização eram muito altos. Então, somando a essa problemática as consequências advindas de tais obras, passaram a ser realizadas obras de recuperação dos meios hídricos. Segundo Garcias e Afonso (2013), a renaturalização tem como objetivos:

- recuperar os rios e córregos de modo a regenerar o mais próximo possível a biota natural, mediante manejo regular ou de programas de renaturalização;

- preservar as áreas naturais de inundação e impedir quaisquer usos que inviabilizem tal função.

Em cidades com infraestrutura urbana já desenvolvida, recuperar as características naturais de um rio pode ser extremamente complicado tendo em vista a insuficiência da área de várzea para que ele crie meandros próprios ou a necessidade de retirar vias de alta demanda de fluxo do seu local.

De acordo com Brenner e Guasselli (2014), a recuperação apresenta as seguintes vantagens para a cidade: diminuir inundaçóes, evitar períodos de estiagem, reduzir processos erosivos e não alterar a planície de inundaçáo a jusante. 
As técnicas de implantação variam desde medidas estruturais a não estruturais, sendo uma complementar à outra. Os estudos de Calderari e Maragno (2013) exemplificam bem essa ideia, pois envolvem a simulação da renaturalização do rio Jataí, em Uberlândia, Minas Gerais, apresentando intervençôes diretas e preventivas. As diretas envolvem as etapas de reinserção da rede hídrica, o restabelecimento ecológico, a incorporação da paisagem construída e o estabelecimento dos links ecológicos, que possibilitam a reconexão do tecido urbano com o meio biótico em todo o sistema. Já as preventivas abrangem a gestão e a educação ambiental, os corredores, as áreas e as ruas verdes e as áreas urbanizáveis, que devem promover o bom desempenho das intervençóes diretas e auxiliá-las. Rezende e Araújo (2015) atentam, em suas pesquisas, para uma parte importante do processo: a gestão participativa.

O planejamento urbano e ambiental sempre deve ter enfoque na gestão participativa, observando diversas açóes voltadas para a inclusão da população em processos decisórios. Dessa forma, a atuação do Estado, em parceria com a sociedade na gestão das políticas públicas contribui para legitimar as açôes, sob uma perspectiva de que as deliberações e escolhas devem ser feitas pelas pessoas que a ela estão submetidas, mediante um diálogo cada vez mais participativo (REZENDE; ARAÚJO, 2015, p. 3).

Esse é um dos ingredientes para o sucesso dos exemplos no exterior, pois "Os projetos internacionais apresentam como principal ponto em comum [...] o envolvimento da população no processo, o que garante que o mesmo seja duradouro" (ALENCAR, 2017, p. 82). Ou seja, pode-se concluir que, além de obras e intervenções no meio físico, as medidas não estruturais, como a criação de leis e educação da população, são de suma importância para esse processo e para sua conservação.

$\mathrm{Na}$ linha de conservação, também se pode incluir obras que tragam lazer à população, criando um vínculo entre ela e o rio. Segundo Foloni e Constantino (2016), para ocorrer a recuperação dos recursos hídricos nas cidades é fundamental que haja a conscientização da população para que as medidas sejam duradouras. Tais providências seriam a implantaçáo da infraestrutura verde que, segundo Gorski (2015 apud FOLONI; CONTANTINO, 2016), é o estabelecimento de áreas abertas e vegetadas com jardins de infiltração, biovaleta e outras medidas de infiltração das águas fluviais. Para Mascaró (2013 apud ARAUJO; RIBEIRO, 2015), a infraestrutura verde é um conjunto de redes multifuncionais de fragmentos permeáveis e vegetados, utilizando arborização viária, distribuição equilibrada de áreas verdes, controle da impermeabilização do solo e drenagem pluvial. Em seus estudos, Araujo e Ribeiro (2015) concluíram que, para ser possível a implantação da infraestrutura verde, é necessário fazer com que a população reflita sobre a degradação 
do meio ambiente, de modo a conseguir conciliar essas mudanças com o bem-estar social.

Um bom exemplo de infraestrutura verde seriam os parques lineares. Como explica Medeiros (2016, p. 17): “Os parques lineares são equipamentos que abrigam a biodiversidade local, buscando conciliar a problemática ambiental aos usos antrópicos, utilizando-se de um paisagismo baseado em preceitos ecológicos”. Como outros exemplos, pode-se ainda citar corredores verdes, alagados, florestas preservadas ou plantadas com espécies nativas, entre outros. Logo, entende-se que é indispensável um bom entendimento entre governo e população para que a renaturalização seja vista com bons olhos, além de obras que criem vínculos com os habitantes, de modo que a melhor decisão possa ser tomada. No entanto, a sustentabilidade pode ser envolvida não só em obras complementares, mas também durante no processo das obras de retomada das condiçôes naturais do rio.

Claramente são obras que poderiam ser implementadas na cidade de São Paulo e que trariam apenas benefícios à população. Além disso, Rowe (2013) garante que tirar uma via expressa em uma grande cidade não foi problema para Seul, pois "o governo metropolitano rapidamente proveu mais transporte público, metrô e um ônibus especial no centro, além de faixas reversíveis nas ruas já existentes e outras opçôes de vias”. Mais um grande exemplo para São Paulo, que sofre com seu insuficiente transporte público.

Ainda pensando na cidade de São Paulo, Bueno e Henkes (2016) estudaram os três tipos de poluição do rio Tietê que precisam ser solucionadas: a poluição industrial, a poluição difusa (lixo) e a poluição por esgoto doméstico. A melhor solução para recuperar o rio seria o aumento da rede de saneamento urbano e a restrição do lançamento de esgoto clandestino no rio. Além disso, seria necessário aumentar as margens para evitar transbordamento, retirar as ocupaçóes irregulares nas margens do rio e impedir o lançamento de produtos químicos. Tzortzis e Kniess (2016) apontam a despoluição do rio Mandaqui, também na cidade, e vários benefícios advindos dessa ação, como a melhora visual do bairro ao seu redor e do extermínio do forte odor que o córrego exalava, ou seja, a qualidade de vida dessa população foi aprimorada. A iniciativa foi da Companhia de Saneamento Básico do Estado de São Paulo (Sabesp) em parceria com o Governo do Estado de São Paulo e a Prefeitura do Município de São Paulo, que criaram um projeto denominado Córrego Limpo, que objetiva despoluir os córregos de São Paulo, pretendendo expandir seus resultados para o rio Tietê, entre muitos outros. Jacobi, Fracalanza e Silva-Sánchez (2015) também realizaram estudos sobre a cidade e o projeto citado anteriormente, e concluíram que um dos meios para a manutenção desses rios recuperados seria o estabelecimento de parques lineares.

Com esses dados em mente, a presente pesquisa objetiva discutir a técnica de renaturalização de córregos e rios para a melhoria da paisagem urbana e para a integração 
da população com o recurso hídrico, além de minimizar problemas com os sistemas de drenagem que se tornaram ineficientes no decorrer dos anos, devido ao crescimento urbano e à diminuição de áreas verdes e várzeas. Assim, o objetivo geral deste trabalho é analisar a viabilidade da renaturalização de córregos e rios em ambientes urbanos na região metropolitana de São Paulo, e o objetivo específico é avaliar os propósitos da renaturalização de córregos e rios em ambientes urbanos, condicionantes técnicos, metodologias adotadas e limitaçôes.

\section{METODOLOGIA}

\subsection{Introduçáo}

O bairro Bela Aliança, onde foi aplicado o estudo de caso, pertence ao distrito da Lapa, no município de São Paulo, e foi fundado na década de 1920. Na época, foi iniciada a implantaçáo de bairros-jardins na cidade, que apresentavam traçado sinuoso, ruas com intensa arborização e lotes grandes destinados à construção de residências unifamiliares. Ao longo dos últimos 20 anos, as áreas adjacentes do bairro passaram por grande processo de verticalização e, consequentemente, houve maior impermeabilização do solo e aumento do escoamento superficial, sobrecarregando o sistema de drenagem da região, originando o problema das inundaçôes por ocasião das chuvas de verão, que são rápidas porém de grande magnitude. Por causa desses eventos, a bacia tem recebido algumas obras hidráulicas destinadas para esses fins, como reservatório de detenção e estruturas superficiais para a melhora das condições de escoamento.

O bairro foi projetado com a implantação de lotes seguindo a premissa de afastamento dos recursos hídricos, o que auxiliou na preservaçáo da mata ciliar e do recurso hídrico, criando áreas verdes no seu entorno. Com a urbanização ao longo dos anos, houve a necessidade de instalação de equipamentos institucionais, como escolas, creches e postos de saúde, e muitas áreas verdes foram destinadas ao uso dessas estruturas, inclusive a área onde se propóe a renaturalização.

Para este estudo, utilizaram-se as técnicas de renaturalização no córrego que foi canalizado em seção fechada durante a implantação do loteamento do bairro. Esse córrego é afluente do córrego Hamburguesa, que, por sua vez, deságua no rio Tietê.

Para a elaboração deste artigo, fizemos o levantamento de dados do local, por meio de visita à Prefeitura Municipal de São Paulo para a obtenção de informaçóes sobre a área estudada, como plantas topográficas da região, plantas as built e alguns relatórios 
sobre as situaçóes atual e anterior que fossem importantes. As plantas foram disponibilizadas, porém, por se tratar de um projeto muito antigo, não foi possível o acesso às plantas as built. Em continuidade ao levantamento de dados, foi realizada uma visita técnica ao local, para que, a partir dessa análise preliminar, fosse possível o planejamento das possibilidades de projeto. Com essas investigaçóes, observou-se que, no local onde se pretende propor a renaturalização, está implantada uma tubulação de concreto de diâmetro 1,50 m, a qual acompanha aproximadamente a declividade do terreno.

Optou-se pela elaboração de um projeto de renaturalização de um pequeno trecho de cabeceira do córrego de aproximadamente 350 metros por se encontrar parcialmente livre de construçôes particulares, principalmente de prédios. A Figura 1 mostra a área onde será proposta a intervenção, que consiste na substituição da tubulação que escoa a vazão fluvial por uma calha aberta com margens.

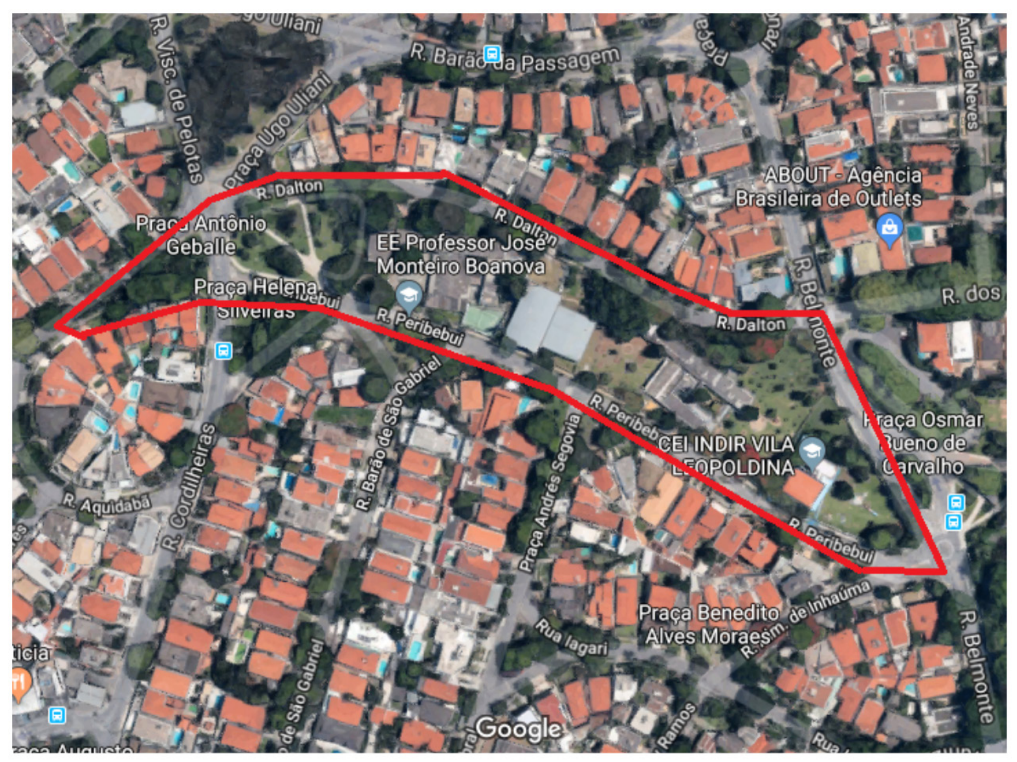

Figura 1 Foto via Satélite da área a ser modificada.

Fonte: Google Maps (2018).

O primeiro procedimento realizado foi a delimitação da área de drenagem afluente à área de estudo, para que fosse possível a elaboração do estudo hidrológico que fornece a vazão de projeto. $\mathrm{O}$ conhecimento dessa vazáo estabelece o tamanho da calha necessária para escoá-la. 
Além da seção hidráulica, faz-se necessário disponibilizar margens atendendo à legislação municipal de 15 metros sem ocupação dos lados, espaço que pode comportar, por exemplo, um parque com equipamentos de lazer e paisagismo.

\subsection{Estudo hidrológico}

O estudo hidrológico que objetivou investigar a vazão veiculada através do córrego estudado foi realizado com a metodologia método racional, que indiretamente estabeleceu uma relação entre a chuva e o escoamento superficial de modo simplificado em bacias pequenas. Podem ser consideradas bacias pequenas aquelas com áreas menores de $3 \mathrm{~km}^{2}$ ou que tenham tempo de concentração menor do que uma hora. A Equaçáo 1 a seguir define o método racional:

$$
Q p=0,275 . C . I . A
$$

Em que:

Qp é a vazão de pico em $\mathrm{m}^{3} / \mathrm{s}$;

C é o coeficiente adimensional relacionado à parcela da chuva total que se transforma em chuva excedente e com os efeitos de armazenamento na bacia; no caso em que os efeitos de armazenamento sejam desprezados, o coeficiente $\mathrm{C}$ é chamado de coeficiente de escoamento superficial e exprime apenas a parcela da chuva total que se transforma em chuva excedente;

A é a área da bacia em $\mathrm{km}^{2}$;

I é a intensidade média da chuva em $\mathrm{mm}$ /hora, considerada constante durante sua duração.

O princípio do método racional é assumir que o tempo de concentração (tc) de uma bacia equivale ao tempo de duração da chuva, considerando que esta tem regime constante e está uniformemente distribuída.

A delimitação da bacia hidrográfica da área de estudo foi segmentada nas áreas de escoamento, conforme a Figura 2. A região traçada em verde refere-se à área de influência de escoamento inicial que se utilizou para determinar a vazão inicial do córrego, ou seja, aquela que vai adentrar a calha renaturalizada. Por sua vez, a região traçada em vermelho refere-se à área de influência total do escoamento, usada no cálculo da vazão que chegará ao fim da calha renaturalizada, ou seja, a vazão final ou vazão crítica. $\mathrm{O}$ traçado rosa corresponde ao maior percurso que a água escoa até o início do córrego que será renaturalizado, importante para a determinação do tempo 
de concentração da bacia. Já o traçado amarelo equivale à extensão que a água percorrerá no córrego.

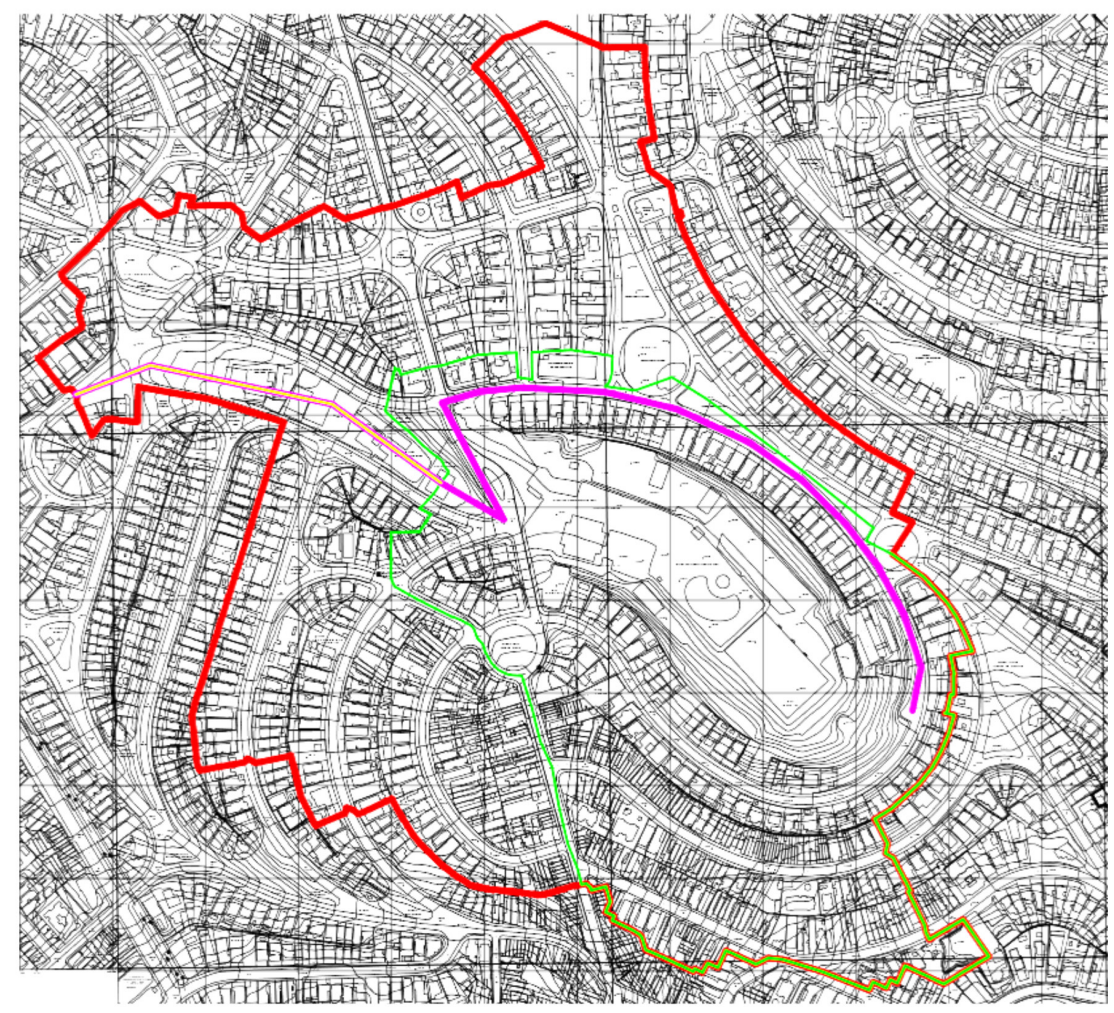

Figura 2 Bacia hidrográfica em estudo.

Fonte: Adaptada de São Paulo (2018).

Analisando a bacia hidrográfica em planta e por meio de vistorias, foi possível chegar à conclusão de que o coeficiente de escoamento superficial da área, que é utilizado na vazão inicial, é 0,50 . Já o coeficiente de escoamento superficial da bacia como um todo é de 0,20, respeitando o intervalo imposto pelo Manual de drenagem e manejo de águas pluviais, da Prefeitura Municipal de São Paulo (SÃO PAULO, 2012).

O tempo de concentração é um dos parâmetros críticos do método racional. Existem diversas fórmulas para sua determinação, que variam de acordo com suas características. Foi possível associar a bacia à fórmula de George Ribeiro (Equação 2), adequada para bacias urbanas de 6 a 600 ha: 


$$
\mathrm{tc}=\frac{16 \cdot L}{(1,05-0,2 p) \cdot(100 \cdot D)^{0,04}}
$$

Em que:

tc é o tempo de concentração (min);

L é o comprimento do talvegue $(\mathrm{km})$;

$\mathrm{D}$ é a declividade média da bacia $(\mathrm{m} / \mathrm{m})$ - definida por:

$D=\frac{\text { maior cota }- \text { menor cota }}{\text { Ltalvegue }}$

$p$ é a fração da área da bacia coberta com vegetação (adimensional).

A partir das tabelas pode-se concluir que:

$$
\begin{gathered}
\text { tc verde }=\frac{16 \cdot 0,925}{(1,05-0,2 \cdot 0,5) \cdot(100 \cdot 0,044)^{0,04}} \rightarrow t \text { c verde }=14,687 \mathrm{~min} \\
\text { tc vermelha }=\frac{16 \cdot 1,269}{(1,05-0,2 \cdot 0,33) \cdot(100 \cdot 0,040)^{0,04}} \rightarrow \text { tc vermelha }=19,527 \mathrm{~min}
\end{gathered}
$$

Estudos recentes mostram que a equação do Instituto de Astronomia, Geofísica e Ciências Atmosféricas (IAG) tende a superestimar os valores da precipitação em até 25\% em comparação com a fórmula de Sampaio-Wilken, portanto, para resultados mais próximos da realidade, será utilizada a de Sampaio-Wilken (Equação 3).

$$
i=K \cdot \frac{\operatorname{Tr}^{m}}{(t+t o)^{n}}
$$

Em que:

$\mathrm{i}=$ intensidade média da chuva $(\mathrm{mm} / \mathrm{min})$;

$\mathrm{t}$ = duração da chuva (min), considerado igual ao tempo de concentração da bacia;

$\mathrm{T}$ = período de retorno (anos) - adotado 25 anos devido ao espaço existente (pequeno) e a outras obras pequenas que também utilizam o mesmo período;

$$
\begin{aligned}
& \mathrm{m}=0,172 \\
& \mathrm{n}=1,025 \\
& \text { to }=22 \\
& \mathrm{~K}=57,71
\end{aligned}
$$


Logo:

\section{Cálculo da vazáo afluente à estrutura hidráulica $(\mathrm{Qp})$}

$$
\begin{aligned}
& i \text { verde }=57,71 \cdot \frac{25^{0,172}}{(14,687+22)^{1,025}} \rightarrow i \text { verde }=2,501 \frac{\mathrm{mm}}{\mathrm{min}}=150,046 \frac{\mathrm{mm}}{\mathrm{h}} \\
& i \text { vermelha }=57,71 \cdot \frac{25^{0,172}}{(19,527+22)^{1,025}} \rightarrow \text { i vermelha }=2,202 \frac{\mathrm{mm}}{\mathrm{min}} \\
& =132,148 \frac{\mathrm{mm}}{\mathrm{h}} \\
& Q p=0,275 . C . I \cdot A \\
& \text { Qp verde }=0,275 \cdot 0,5 \cdot 150,046.0,273 \rightarrow 5,632 \mathrm{~m}^{3} / \mathrm{s} \\
& \text { Qp vermelha }=0,275 \cdot 0,651 \cdot 132,148 \cdot 0,548 \rightarrow 12,964 \mathrm{~m}^{3} / \mathrm{s}
\end{aligned}
$$

Cálculo da vazão máxima da tubulação $\mathrm{D}=1,50 \mathrm{~m}$ implantada no local $(\mathrm{Q})$ :

$$
\begin{gathered}
i=\text { declividade do rio todo }=\frac{737,29-729,48}{374,50}=0,021 \frac{\mathrm{m}}{\mathrm{m}} \\
i=\text { declividade entre dois } P V s=\frac{737,29-735,44}{98,22}=0,019 \frac{\mathrm{m}}{\mathrm{m}} \\
\frac{y}{D}=0,9 \rightarrow K_{1}=0,661 \\
D=\frac{M}{K_{1}} \rightarrow 1,50=M=0,9915 \\
M=\left[\frac{Q \cdot \eta}{\sqrt{i}}\right]^{3 / 8} \rightarrow 0,9915=\left[\frac{Q \cdot 0,014}{\sqrt{0,02}}\right]^{3 / 8}=9,870 \mathrm{~m}^{3} / \mathrm{s}
\end{gathered}
$$

Logo:

$\mathrm{Q}=9,870 \mathrm{~m}^{3} / \mathrm{s}<12,964 \mathrm{~m}^{3} / \mathrm{s}$

Comparando-se a vazão do estudo hidrológico realizado $\left(12,964 \mathrm{~m}^{3} / \mathrm{s}\right)$, período de retorno de 25 anos, à máxima vazão suportada pela tubulação implantada no local $\left(9,870 \mathrm{~m}^{3} / \mathrm{s}\right)$, observa-se que, para as condiçóes atuais da bacia, essa tubulação tornou-se insuficiente para uma eficiente drenagem, o que justifica as inundaçóes que têm ocorrido na área nos últimos anos.

\subsection{Estudo hidráulico}

Para a realização do dimensionamento da seção transversal do córrego, foi escolhida a forma retangular para que houvesse maior disponibilização de espaço para o 
parque linear. Os revestimentos escolhidos para a seção foram piso permeável para a base, favorecendo a infiltração, e gabião para as paredes, cujo objetivo é conter os terrenos das margens e diminuir a velocidade do escoamento, uma vez que apresenta rugosidade mais elevada que o concreto. Além desses materiais rugosos, optou-se por projetar o fundo do rio em degraus com uma leve declividade entre eles, para que o escoamento ocorra com velocidade reduzida, retardando o pico de cheia a jusante e evitando inundaçôes. Para o dimensionamento hidráulico, foi utilizada a equação de Manning (Equação 4) e, para a ponderação do coeficiente de rugosidade de Manning, a Equação 5.

$$
\begin{gathered}
\mathrm{Q}=\frac{1}{\eta} * \mathrm{~S} * R H^{2 / 3} * \sqrt{i} \\
\eta_{\mathrm{e}}=\left[\frac{P 1 * \eta 1^{\frac{3}{2}}+P 2 * \eta 2^{\frac{3}{2}}}{P 1+P 2}\right]^{2 / 3}
\end{gathered}
$$

\section{TABELA 1}

\begin{tabular}{|c|c|c|c|}
\hline \multicolumn{4}{|c|}{ Dimensionamento hidráulico } \\
\hline Seção & A-A & B-B & $\mathrm{C}-\mathrm{C}$ \\
\hline Vazão (Q) $\left[\mathrm{m}^{3} / \mathrm{s}\right]$ & 5,632 & 10,270 & 12,964 \\
\hline Talude [m] & 1,540 & 2,080 & 2,080 \\
\hline Número de Manning equivalente ( $\eta$ e) & 0,029 & 0,029 & 0,029 \\
\hline Inclinação (i) [m/m] & 0,021 & 0,035 & 0,023 \\
\hline Área molhada $(\mathbf{S})\left[\mathrm{m}^{2}\right]$ & 1,925 & 2,600 & 3,453 \\
\hline Perímetro molhado $(\mathrm{P})[\mathrm{m}]$ & 4,330 & 5,410 & 5,820 \\
\hline Raio hidráulico (Rh) [m] & 0,445 & 0,481 & 0,593 \\
\hline Profundidade do canal $(\mathrm{Y})[\mathrm{m}]$ & 1,540 & 2,080 & 2,080 \\
\hline Base (b) $[\mathrm{m}]$ & 1,250 & 1,250 & 1,660 \\
\hline
\end{tabular}

Cálculo das seções hidráulicas

Fonte: Elaborada pelos autores (2018). 
A partir da profundidade e da base do canal encontradas (Tabela 1), obteve-se o dimensionamento da seção, conforme esquematizada e representada pela Figura 3.

Corte A-A

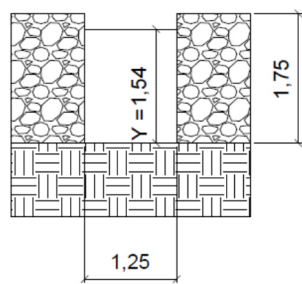

Corte B-B

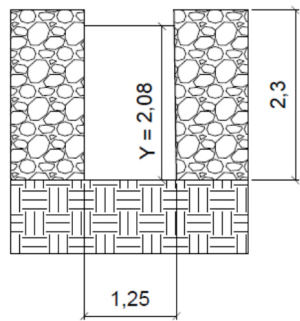

Corte C-C

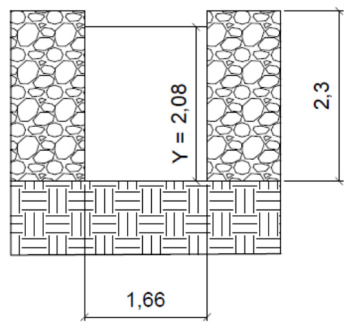

Figura 3 Seções transversais do canal projetado.

Fonte: Elaborada pelos autores.

Na sequência, apresenta-se o perfil longitudinal do córrego (Figura 4), com previsão de degraus de acordo com a declividade do terreno. Os degraus são importantes para a reduçáo da velocidade do escoamento.

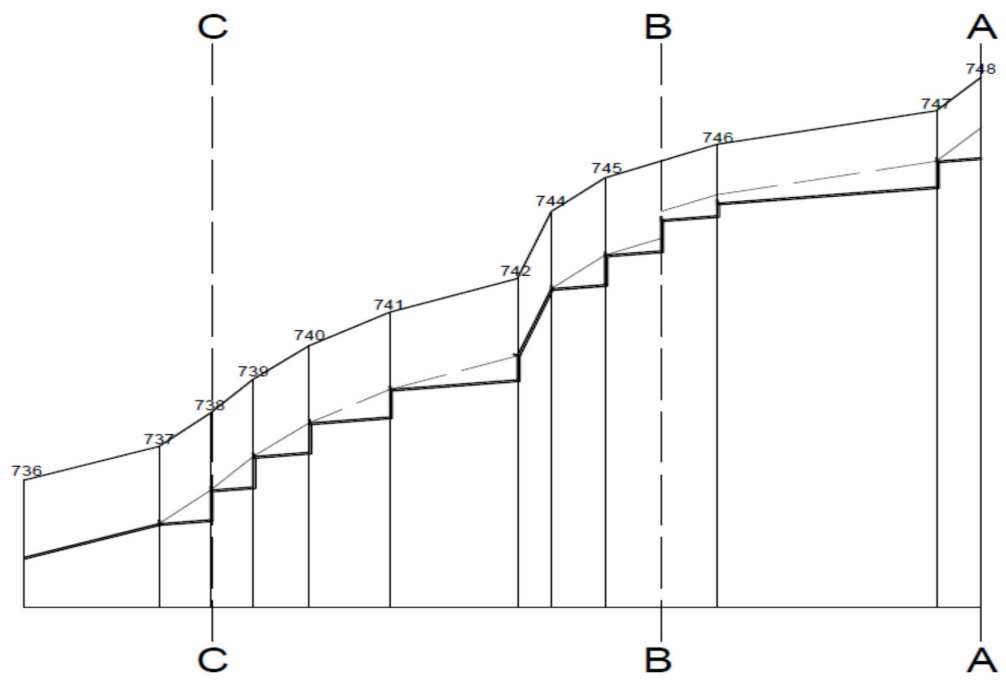

Figura 4 Perfil longitudinal do canal em escala distorcida.

Fonte: Elaborada pelos autores (2018). 


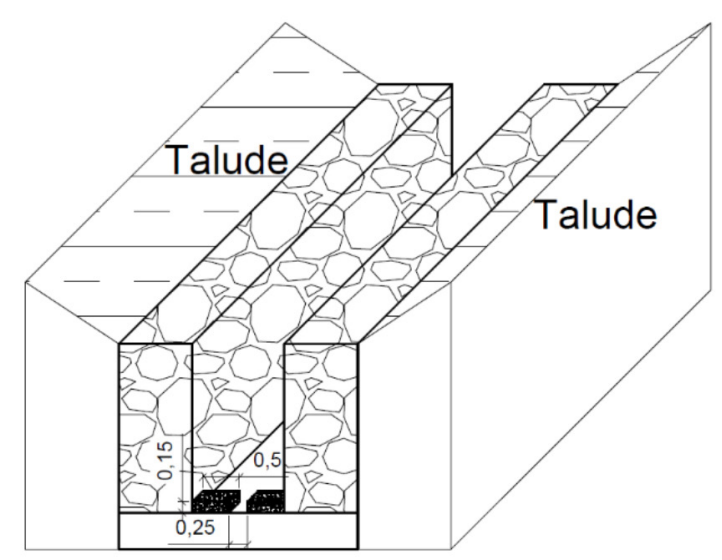

Figura 5 Detalhe dos degraus.

Fonte: Elaborada pelos autores (2018)

\section{RESULTADOS E DISCUSSÃO}

A partir das investigaçôes das condiçôes locais, do estudo hidrológico realizado e da idealização de uma seção hidráulica apropriada, observou-se a possibilidade de renaturalização do trecho estudado e a instalação de um parque linear ao longo das margens. A Figura 6 a seguir mostra uma sugestão de implantação com a calha aberta e as margens, com pista de corrida e ciclovia, equipamentos de ginástica, espaço para foodtrucks e mesas, quadras poliesportivas e banheiros com vestiários, parquinhos com brinquedos destinados às crianças e um pet place, além de uma vasta área arborizada. A solução técnica nesse caso veio acompanhada de exemplos de como as margens do rio renaturalizado poderiam servir como meio de lazer à população local, melhorando sua qualidade de vida e ajudando no desenvolvimento da conscientizaçáo de preservação do ambiente em questão. 


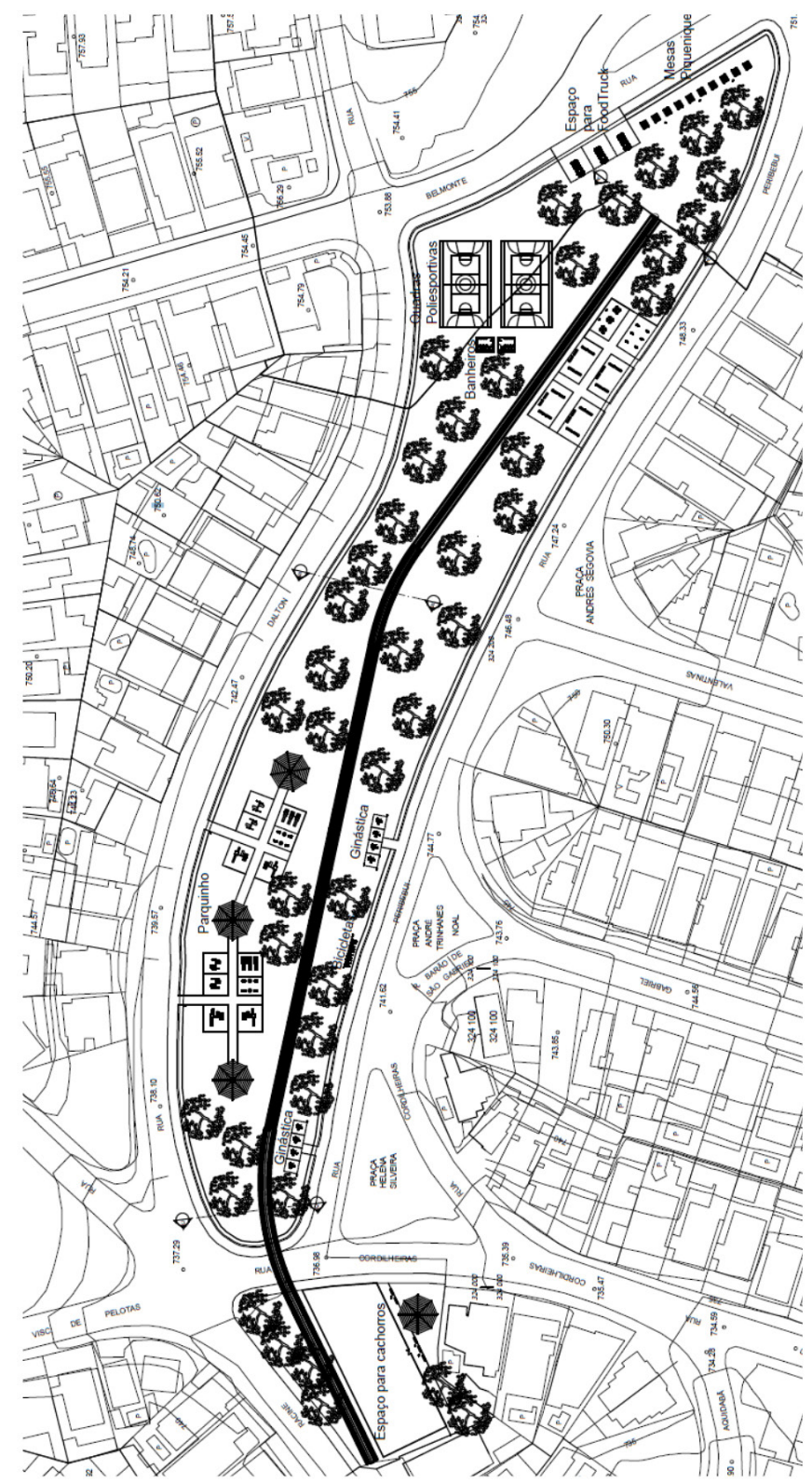

Figura 6 Simulação da renaturalização.

Fonte: Elaborada pelos autores (2018). 
Como mencionado anteriormente, nos últimos anos foram observadas inundaçóes nas ruas a jusante da área de projeto. Um benefício adicional da renaturalização proposta seria a minimização do problema, uma vez que o tratamento dado à seção hidráulica contempla a redução da velocidade do escoamento, além de uma reservação parcial no próprio canal, retardando a onda de cheia.

Como qualquer intervenção técnica, existem também desvantagens, como a manutenção do local, que, nesse caso, será mais complexa e dispendiosa, posto que serão fundamentais a limpeza e o desassoreamento do córrego periodicamente. O parque linear, possivelmente implantado junto à renaturalização, requer também manutenção, além de gestão.

Sabe-se que no Brasil os serviços de manutenção ainda são negligenciados por vários motivos, como a dependência de contratos que requerem processos de licitação e a possibilidade de esses serviços possivelmente estarem contidos em um contrato maior - por exemplo, os serviços de desassoreamento intercalados por grandes períodos que não necessariamente representam o tempo mínimo necessário para uma próxima limpeza. $\mathrm{O}$ envolvimento da população que mora no entorno pode ser benéfico para a manutenção da área. O terreno, que foi utilizado para a elaboração do processo de renaturalização do corpo hídrico, abriga dois equipamentos institucionais importantes: uma escola estadual de ensinos Fundamental II e Médio e uma creche municipal, as quais, caso o projeto seja implantado, deverão ser realocadas, constituindo uma segunda desvantagem significativa. Uma vez que esses equipamentos não podem permanecer no local, faz-se necessário o estudo de área, a fim de encontrar uma localização adequada que atenda às demandas do Centro de Educação Infantil (CEI), organização que atende crianças de zero a três anos e 11 meses, e da Escola Estadual José Monteiro Boa Nova.

Nas proximidades, existe um clube da Prefeitura Municipal de São Paulo e a Escola Estadual Professor Reynaldo Porshat. O clube, que é um local muito frequentado aos fins de semana e feriados, porém pouco visitado durante a semana, possui área e infraestrutura disponíveis para comportar a CEI, possibilitando, assim, que o papel institucional possa ser exercido durante a semana e mantenha a sua função atual durante os finais de semana. Quanto aos alunos da escola estadual, os quais teriam de ser igualmente realocados, eles poderão ser transferidos para a Escola Estadual Professor Reynaldo Porshat, localizado a, aproximadamente, 500 metros do local atual do equipamento. 


\section{CONCLUSĀO}

Nas grandes cidades muitos acontecimentos resultaram na perda de áreas verdes, em São Paulo não poderia ser diferente. A legislação federal, a mais restritiva e clara sobre o assunto na forma da Lei $n^{\circ} 12.651 / 2012$, estabelece normas gerais sobre a proteção da vegetação e áreas de preservação permanente, sendo estas as faixas marginais de cursos da água natural, perene e intermitente. Segundo essa lei, deve-se manter um afastamento de 30 metros da borda do leito regular, a fim de proteger a vegetação, o recurso hídrico, a estabilidade geológica e o bem-estar da população.

Constatou-se que a renaturalizaçáo pode ser implantada mesmo em uma área urbanizada, pois, por meio de pesquisas, surgiram evidências da possibilidade de mudar um local urbanizado, já com uma função estrutural no meio ao qual está inserido, para outro, também funcional, que potencializa a apreciação e utilização do meio público.

A importância de um rio na configuração histórica e geográfica do espaço urbano está não apenas na convivência e no uso público, mas também no lazer ao ar livre e nas relaçóes entre os habitantes daquele bairro. Em áreas urbanas, a tarefa de recuperação dos rios torna-se essencial para o controle de enchentes e a preservação dos níveis de água subterrânea. A criação de parques municipais em áreas de várzea é uma alternativa que cria espaços recreativos para a população, e, com essa medida, o poder público pode impedir que áreas de várzea sejam ocupadas indevidamente. Outra grande vantagem da renaturalização de rios urbanos é a economia, pois os custos de implantação dessas medidas são mais baixos que os transtornos físicos e financeiros gerados pelas enchentes. A abertura de canais possui custo reduzido quando comparado às obras de detenção e retenção que pretendem diminuir a incidência de enchentes em regiốes urbanas. No entanto, não basta apenas planejar medidas de revitalização das margens e das matas ciliares, mas sim agir no sentido de recuperar a qualidade das águas, evitando os despejos ilegais de esgotos não tratados.

A manutenção é indispensável, contrariando a posição de muitas administrações municipais brasileiras, seja por negligência, seja pelas dificuldades na contratação desses serviços com processos demorados. Náo basta executar uma obra resultante de um bom projeto, são necessários outros enfrentamentos que nem sempre são previstos. Alguns países investiram com sucesso no envolvimento da população na manutenção da obra pública, e as gestóes municipais poderiam aproveitar essas boas experiências para o Brasil. 


\title{
RENATURALIZATION OF URBAN RIVERS AND STREAMS
}

\begin{abstract}
The process of renaturalization seeks to recuperate a river or stream by reestablishing some natural characteristics to integrate the water resource into the urban landscape. When applied in cities, renaturalization rescues natural resources that disappeared over the years because of advanced urbanization and consequently the need for space. Due to domestic sewage, polluted rivers have contributed a lot to the culmination of water resources that were degraded and considered a disease-cause from the environmental point of view. Implementing the technique can minimize problems like floods resulting from excessive waterproofing of the soil in urban areas. To maintain the surroundings of the watercourse is to consider the interaction between the river and the population. We have chosen the linear park for this article, where people can interact with the site and develop thoughts about environmental preservation. By elaborating a renaturalization on a river in the metropolitan region of São Paulo, this project demonstrates that the technique may be possible even in a big city. However, preliminary studies are needed, so the implantation project can be feasible and benefit the population.
\end{abstract}

Keywords: Renaturalization. Linear park. Urban drainage.

\section{REFERÊNCIAS}

ALENCAR, J. Bacias hidrográficas urbanizadas: renaturalização, revitalização e recuperação. Um estudo da bacia do Jaguaré. 2017. 310 f. Tese (Doutorado em Engenharia Hidráulica) Universidade de São Paulo, São Paulo, 2017.

ARAUJO, E. C. de; RIBEIRO, N. F. Cidades verdes: contribuiçôes para o debate sobre rios urbanos e corredores verdes. Periódico Técnico e Científico Cidades Verdes, v. 3, n. 5, p. 117-132, 2015.

BRENNER V. C.; GUASSELLI L. A. Análise da viabilidade do processo de renaturalização de um trecho do canal retificado do rio Gravataí, Rio Grande do Sul, Brasil. In: SIMPÓSIO DE GEOTECNOlOGIAS NO PANTANAL, 5., 2014, Campo Grande. Anais [...] Campo Grande: Embrapa Informática Agropecuária/Inpe, 2014. p. 593-601. Disponível em: https:// www.geopantanal.cnptia.embrapa.br/2014/cd/p92.pdf. Acesso em: 13 ago. 2021. 
BRONCANELI, P. F.; STUERMER, M. M. Renaturalização de rios e córregos no município de São Paulo. Exacta, São Paulo, v. 6, n. 1, p. 147-156, jan./jun. 2008.

BUENO, M. G.; HENKES, J. A. Revitalização do rio Tietê: uma opção viável. Gestão e Sustentabilidade Ambiental, Florianópolis, v. 5, n. 1, p. 516-534, abr./set. 2016.

CALDERARI, E. S.; MARAGNO, A. L. F. C. Águas urbanas: um novo olhar para o planejamento urbano nas cidades. Revista Nacional de Gerenciamento de Cidades, v. 1, n. 2, p. 20-41, 10 nov. 2013. Disponível em: http://dx.doi.org/10.17271/23188472122013444. Acesso em: 14 out. 2021.

ESPOSI, S. A.; TAKADA, M. A.; SILVA, P. J. da. Identificação das técnicas de bioengenharia passiveis de serem aplicadas ao ribeirão dos meninos, visando a sua renaturalização. 2016. $20 \mathrm{f}$. Trabalho de Conclusão de Curso (Graduação em Engenharia Civil) - Instituto Mauá de Tecnologia, São Paulo, 2016.

FOLONI, F. M.; CONSTANTINO, N. R. T. Reconciliando rios urbanos com a paisagem: Levantamento de estudos de caso. Revista Nacional de Gerenciamento de Cidades, v. 4, n. 23, p. 78-95, 14 set. 2016. Disponível em: http://dx.doi.org/10.17271/2318847242320161309. Acesso em: 14 out. 2021.

GARCIAS, C. M.; AFONSO, J. A. C. Revitalização de rios urbanos. Revista Eletrônica de Gestão e Tecnologias Ambientais (gesta), v. 1, n. 1, p. 131-144, 2013.

GOOGLE MAPS. Versão Satélite. Imagery 2018 CNES/Airbus, Maxar Technologies. [2021].

JACOBI, P. R.; FRACALANZA, A. P.; SILVA-SÁNCHEZ, S. Governança da água e inovação na política de recuperação de recursos hídricos na cidade de São Paulo. Cadernos Metrópole, v. 17 , n. 33, p. 61-81, maio 2015 .

MEDEIROS, J. M. M. Um parque linear para o Lago Paranoá: realidade ou utopia? Revista Varau, Brasília, DF, n. 4, p. 17-31, 2016.

REZENDE, G. B. de M.; ARAÚJO, S. M. S. de. Rios urbanos: reflexôes sobre os aspectos ambientais e urbanos de suas margens rumo a uma perspectiva integradora e participativa. Revista Espacios, v. 36, n. 23, p. 3, 13 set. 2015. Disponível em: http://www.revistaespacios. com/a15v36n23/15362303.html. Acesso em: 14 out. 2021.

ROWE, P. G. Os resultados e a história do projeto de restauração do Cheonggyecheon, em Seul, que derrubou uma via expressa elevada e propôs um espaço de lazer em torno ao córrego. Revista Pini, 2003. Disponível em: http://www.au.pini.com.br/arquiteturaurbanismo/234/restauracao-do-cheonggyecheon-seul-coreia-do-sul-296126-1.aspx. Acesso em: 14 out. 2021.

SÃO PAULO (Cidade). Geosampa 2018. Mapa digital da cidade de São Paulo. São Paulo: Prefeitura da cidade de São Paulo, 2018. Disponível em: http://geosampa.prefeitura.sp.gov.br/ PaginasPublicas/_SBC.aspx. Acesso em: 12 ago. 2021.

SÃO PAULO (Cidade). Secretaria Municipal de Desenvolvimento Urbano. Manual de drenagem e manejo de águas pluviais: aspectos tecnológicos: fundamentos. São Paulo: SMDU, 2012. $2 \mathrm{v}$. 
TZORTZIS, P. S.; KNIESS, C. T. Programa de despoluição de córregos: Programa Córrego Limpo. Iptec - Revista Inovação, Projetos e Tecnologias, São Paulo, v. 4, n. 1, p. 114-128, jan. 2016.

\section{Contato}

Liliane Frosini Armelin

liliane.armelin@mackenzie.br

Tramitação

Recebido em novembro de 2019.

Aprovado em agosto de 2020. 